\title{
Impact of Fluidic Chevrons on Supersonic Jet Noise
}

\author{
Brenda Henderson $^{*}$ and Thomas Norum ${ }^{\dagger}$ \\ NASA Langley Research Center, Hampton, VA,23681
}

\begin{abstract}
The impact of fluidic chevrons on broadband shock noise and mixing noise for single stream and coannular jets was investigated. Air was injected into the core flow of a bypass ratio 5 nozzle system using a core fluidic chevron nozzle. For the single stream experiments, the fan stream was operated at the wind tunnel conditions and the core stream was operated at supersonic speeds. For the dual stream experiments, the fan stream was operated at supersonic speeds and the core stream was varied between subsonic and supersonic conditions. For the single stream jet at nozzle pressure ratio (NPR) below 2.0, increasing the injection pressure of the fluidic chevron increased high frequency noise at observation angles upstream of the nozzle exit and decreased mixing noise near the peak jet noise angle. When the NPR increased to a point where broadband shock noise dominated the acoustic spectra at upstream observation angles, the fluidic chevrons significantly decreased this noise. For dual stream jets, the fluidic chevrons reduced broadband shock noise levels when the fan NPR was below 2.3, but had little or no impact on shock noise with further increases in fan pressure. For all fan stream conditions investigated, the fluidic chevron became more effective at reducing mixing noise near the peak jet noise angle as the core pressure increased.
\end{abstract}

\section{Introduction}

$\mathrm{B}$ ROADBAND shock associated noise characteristics of dual stream jets were a topic of interest in the 1980's as concepts for future supersonic transport aircraft were investigated. More recently, broadband shock associated noise has become a concern on long cruise segments of subsonic commercial aircraft because of high cabin noise exposure levels on crew and passengers. Broadband shock noise occurs when the fan stream of a turbofan engine reaches supersonic speeds and a shock cell structure forms in the exhaust jet. Depending on the core stream conditions, broadband shock associated noise can dominate the acoustic radiation upstream of the engine nozzle exit. Hence, there is a need to develop effective noise reduction techniques that can be deployed when required to eliminate shock noise from dual stream jets. One such technique, that of utilizing fluidic chevron core nozzles, is the subject of this study.

Broadband shock associated noise is the result of interactions between stream disturbances and shock waves in the jet shock cell structure. The original work of Harper-Bourne and Fisher ${ }^{2}$ modeled shock noise by an array of acoustic sources. Peaks in the noise spectrum were shown to be the result of constructive interference between sources. Tam ${ }^{3,4}$ developed a stochastic model in which instability waves interact with waveguide modes used to represent the shock waves. The interaction results in unsteady disturbances that radiate to the far field as broadband shock noise. For dual stream jets, Bhat, Ganz, and Guthrie ${ }^{5}$ have shown that the impact of broadband shock noise on the resulting acoustic radiation is closely tied to the engine cycle and, for some combinations of fan and core stream pressures, increases in the fan nozzle pressure ratio do not lead to increases in acoustic radiation. They introduced a modification to Pack's ${ }^{6}$ equation for shock cell spacings of a single jet to correlate shock cell spacing data obtained in their experiments on dual stream jets.

Reduction of broadband shock noise from single nozzles using fluidic injection has been obtained in recent laboratory tests in which injectors were placed around the external periphery of the jet. Greska and Krothapalli ${ }^{7}$ used both nitrogen and aqueous solutions injected at very high pressure (18 - 56 atm) through small diameter $(0.4$ $0.8 \mathrm{~mm}$ ) nozzles to obtain reductions in both shock noise and mixing noise from a supersonic jet. Norum ${ }^{8}$ used somewhat larger diameter injectors $(0.8-3.2 \mathrm{~mm})$ and showed that broadband shock noise can be virtually eliminated by injecting water at high pressure (10 atm).

\footnotetext{
* Senior Researcher, Aeroacoustics Branch, MS 166, Hampton, VA 23681, AIAA Member.

† Senior Researcher, Aeroacoustics Branch, MS 166, Hampton, VA 23681.
} 
Noise reduction for subsonic dual stream jets using fluidic injection has predominantly focused on fluidic chevrons, nozzles that introduce air at relatively low pressures through slots, holes, or tubes, in order to enhance jet plume mixing. Previous studies using mechanical chevrons (serrations at the nozzle trailing edge that are deflected into the flow) have shown the potential for jet noise reduction ${ }^{9}$. Computational results for the fluidic chevron presented by Kinzie, Henderson, Whitmire, and Abeysinghe ${ }^{10}$ show centerline temperature decay rates and flow structures that are similar to those produced by the mechanical chevron. For dual stream subsonic jets, Henderson, Kinzie, Whitmire, and Abeysinghe ${ }^{11}$ found reductions in mixing noise for second generation core fluidic chevrons injecting air into the core stream that were close to those achieved by mechanical chevrons. The effect of fluidic chevrons on broadband shock associated noise was not investigated in these earlier studies.

The present study investigates the impact of the second-generation core fluidic chevrons used in Ref. 11 on broadband shock noise produced by both dual stream and single stream jets. Air injected into the core stream is expected to alter the stream disturbances and perturb the shock cell structure leading to reductions in the broadband shock noise. The effect on the mixing noise component of the jets is also investigated.

\section{Experimental Approach}

The experiments were conducted in the Low Speed Aeroacoustics Wind Tunnel (LSAWT) at NASA Langley Research Center shown in Fig. 1. The LSAWT provides a simulated flight stream up to Mach numbers of 0.32. The free jet exhausts through a 56 inch square nozzle into a $34 \mathrm{ft}$ long test cell with a $17 \mathrm{ft} \times 17 \mathrm{ft}$ cross section. The floor, ceiling and walls are treated with fiberglass wedges. The Jet Engine Simulator (JES), centered in the wind tunnel jet, consists of coannular air streams used to simulate the fan and core streams of an engine nozzle system. Each stream is equipped with a propane-fired, sudden-expansion burner and an electric pre-heater to achieve real engine temperatures of commercial turbo-fan engines.

Acoustic measurements are made with a 28-microphone sideline array located $12 \mathrm{ft}$ from the centerline axis of the JES. The acoustic data are presented here as narrowband power spectra with a bandwidth of $26.4 \mathrm{~Hz}$. The data were calibrated for sensitivity and frequency response of the microphones and corrected for atmospheric absorption using the Shields and Bass ${ }^{12}$ method.

Table 1. Single Stream Experimental Conditions

Table 2. Dual Stream Experimental Conditions

\begin{tabular}{|c|c|c|c|}
\hline $\mathbf{N P R}_{\mathbf{c}}$ & $\mathbf{T T R}_{\mathbf{c}}$ & $\mathbf{N P R}_{\mathbf{f}}$ & $\mathbf{T T R}_{\mathbf{f}}$ \\
\hline 1.61 & 2.13 & 2.23 & 1.05 \\
1.82 & 2.13 & 2.23 & 1.05 \\
2.04 & 2.39 & 2.23 & 1.05 \\
1.61 & 2.26 & 2.35 & 1.17 \\
1.82 & 2.26 & 2.35 & 1.17 \\
2.04 & 2.39 & 2.35 & 1.17 \\
2.17 & 2.46 & 2.35 & 1.17 \\
2.04 & 2.39 & 2.45 & 1.04 \\
2.17 & 2.46 & 2.5 & 1.05 \\
\hline
\end{tabular}

\begin{tabular}{|c|c|}
\hline $\mathbf{N P R}_{\mathbf{c}}$ & TTR $_{\mathbf{c}}$ \\
\hline 1.93 & 1 \\
2.04 & 1 \\
2.17 & 1 \\
2.30 & 2.5 \\
\hline
\end{tabular}

A representative $1 / 9^{\text {th }}$ scale, bypass ratio (BPR) 5 model system was used in the experiments. The baseline model consisted of an externally plugged, 5.07 inch diameter core nozzle with an exit area of $10.98 \mathrm{in}^{2}$ and a 9.45 inch diameter fan nozzle with an exit area of $29.14 \mathrm{in}^{2}$. The baseline core nozzle had a uniform thickness of 0.035" at the trailing edge. For the fluidic chevron investigations, the baseline core nozzle was replaced with one of two second-generation, fluidic-chevron nozzles described in Henderson, Kinzie, Whitmire, and Abeysinghe ${ }^{11}$. The fluidic chevron nozzles introduced air from an air delivery tube in the pylon into six contoured injection passages in the core nozzle as shown in Fig. 2. Two different fluidic

chevron nozzles were used to determine the effect of changing the angle between the injected flow and the core nozzle flow. One fluidic chevron had a shallow injection angle and the other a steep injection angle (the latter being more perpendicular to the core flow direction). A pylon with an angle of $122^{\circ}$ to the microphone array axis was used with all three nozzle configurations.

Acoustic data for a single stream jet were obtained by operating the core nozzle at supersonic speeds and matching the temperatures and pressures in the fan to those of the free jet. Conditions for single stream and dual stream tests are shown in Tables 1 and 2 respectively. The total temperature ratio (TTR) is the ratio of the total temperature to the test cell temperature and the nozzle pressure ratio (NPR) is the ratio of the stagnation pressure to the test cell ambient pressure. The subscripts $\mathrm{c}$ and $\mathrm{f}$ indicate core and fan streams, respectively. All data presented here were obtained at a simulated flight Mach number of 0.1. 


\section{Results}

\section{A. Single Stream Experiments}

Single stream narrowband acoustic spectra for the baseline nozzle and the two fluidic chevron nozzles without injected air are shown at a core NPR of 2.17 in Fig. 3. Observation angles are measured from the core nozzle exit with $180^{\circ}$ being the downstream direction. The injection pressure ratio (IPR) is the ratio of the stagnation pressure of the injected air to the ambient pressure in the test cell. As shown in the figure, the acoustic characteristics of the baseline nozzle are similar to those of the fluidic chevron nozzles with no air injection (IPR $=1.0$ ) in both the upstream direction, where broadband shock noise often dominates the acoustic spectrum, and the downstream direction, which is usually dominated by jet mixing noise. However, since the baseline nozzle is seen to produce slightly higher noise levels than those of the fluidic chevron nozzles, the latter will be used as the baseline from which air injection noise reduction is determined.

A comparison of the acoustic radiation with increasing core NPR for the steep fluidic chevron nozzle with no air injection is shown in Fig. 4. For values of $\mathrm{NPR}_{c}$ up to at least 2.04, broadband shock noise cannot be easily identified in the spectra. At $\mathrm{NPR}_{\mathrm{c}}=2.17$, a well-defined peak [see Fig. 4 (a)] associated with broadband shock noise is found to dominate the spectra for observation angles less than $95^{\circ}$. At the peak jet noise angle [see Fig. 4 (b)], increases in core pressure result in a consistent noise increase at all frequencies, typical of jet mixing noise.

The spectra from Fig 4 at $\mathrm{NPR}_{\mathrm{c}}=1.93$ are repeated in Fig. 5 along with those for the injectors operating at IPR $=$ 2 and 4. At frequencies below about $5000 \mathrm{~Hz}$ there is no effect of fluidic injection in the upstream direction [Fig 4 (a)] and a small decrease in noise level with IPR in the downstream direction [Fig 5 (b)]. At higher frequencies the noise levels at IPR $=4$ increased over those for no injection. The high-frequency noise characteristics in Fig. 5 (b) are similar to those observed in the data for the injectors operating at IPR $=4$ without core flow.

The spectra from Fig 4 at $\mathrm{NPR}_{\mathrm{c}}=2.17$ are repeated in Fig 6 along with those for air injection at IPR $=2$ and 4. Now that a well-defined peak associated with broadband shock noise is present in the upstream narrowband data, the acoustic radiation is significantly impacted by fluidic injection. The peak in the upstream spectrum is substantially reduced by IPR $=2$ and is effectively eliminated when the injection pressure ratio reaches 4 . Increasing IPR also decreases mixing noise at the downstream angles as shown in the spectra in Fig. 6 (b). Again there is some increase in SPL at the higher frequencies as the injection pressure increases. Figure 7 shows that the overall sound pressure level (OASPL) is reduced at all observation angles. The reductions in OASPL at angles less than $120^{\circ}$ are predominantly associated with reductions in broadband shock noise.

The impact of fluid injection on a single stream hot jet was also investigated. Spectra taken at a total temperature ratio $\mathrm{TTR}_{\mathrm{c}}=2.5$ and an $\mathrm{NPR}_{\mathrm{c}}=2.30$ are shown in Fig 8. Because increasing jet temperature increases the ratio of mixing noise to shock noise, the presence of the upstream broadband shock noise peak and its reduction due to air injection are now less conspicuous. Although Fig 8 (b) shows low to mid-frequency noise reduction at IPR=4, the high frequency noise is again amplified by the injected air. The fluidic chevrons had a similar effect on the downstream spectra as they had for the lower temperature jet. The OASPL directivities given in Fig 9 show that the noise reduction for the hot jet are lower than those given in Fig 7 for the cold jet at all but the furthest downstream angles.

\section{B. Dual Stream Experiments}

Results for the fan stream operating at an $\mathrm{NPR}_{\mathrm{f}}$ equal to 2.23 are given in Figs. 10 through 15 . The acoustic spectra for the steep fluidic chevron nozzle with no air injection at a fan NPR equal to 2.23 and $\mathrm{NPR}_{\mathrm{c}}$ between 1.61 and 2.04 are shown in Fig. 10. For the lowest core pressure $\left(\mathrm{NPR}_{\mathrm{c}}=1.61\right)$, a well-defined peak associated with broadband shock noise is identifiable in Fig. 10 (a). As the core pressure increases, the broadband shock noise levels decrease. When the core reaches supersonic speeds $\left(\mathrm{NPR}_{\mathrm{c}}=2.04\right)$, the broadband shock noise peak is nearly imperceptible in the acoustic spectrum. In the peak jet noise downstream direction, [see Fig. 10 (b)], there is a consistent increase in noise with increasing core pressure.

The effect of injection pressure for the steep fluidic chevron nozzle at $\mathrm{NPR}_{\mathrm{c}}=1.61, \mathrm{NPR}_{\mathrm{f}}=2.23$ is shown in Fig. 11. As the injection pressure increases, the broadband shock noise peak in Fig. 11 (a) decreases and the high frequency noise increases. At the peak jet noise angle [see Fig. 12 (b)], air injection appears to have little effect on radiated jet noise. The corresponding OASPL sideline directivity in Fig. 12 shows the decreased noise associated with reductions in broadband shock noise for angles between $45^{\circ}$ and $120^{\circ}$ as well as the smaller effects in the downstream direction. 
A comparison of the OASPL reductions at this condition between the steep and shallow fluidic chevron nozzles is given in Fig 13 for the injection pressure ratio of 3. As has been seen in Figs 11 and 12, the largest noise reductions appear in the upstream angles, where broadband shock noise dominates the acoustic spectra. The steep fluidic chevrons give a greater noise reduction than the shallow fluidic chevron at these angles.

The results for the steep fluidic chevron nozzle operating with a supersonic core jet $\left(\mathrm{NPR}_{\mathrm{c}}=2.04, \mathrm{NPR}_{\mathrm{f}}=2.23\right)$ are shown in Figs. 14 and 15. As the broadband shock noise peak has virtually disappeared at this condition, there are only small effects of air injection on noise in the upstream direction. In the peak noise direction the sideline directivity shows an overall sound pressure level reduction of roughly $2 \mathrm{~dB}$ at an injection pressure ratio of 4 .

Results with the fan stream pressure increased to $\mathrm{NPR}_{\mathrm{f}}=2.35$ are given in Figs. 16 through 20. The acoustic spectra for the steep fluidic chevrons with no air injection with a fan NPR equal to 2.35 and $\mathrm{NPR}_{\mathrm{c}}$ between 1.82 and 2.17 are shown in Fig. 16. The spectra in the upstream direction show a more complicated behavior than that at the lower fan NPR given in Fig 10. For the lowest core pressure $\left(\mathrm{NPR}_{\mathrm{c}}=1.82\right)$, a well-defined peak associated with broadband shock noise is identifiable in Fig. 16 (a). When the core reaches supersonic speed $\left(\mathrm{NPR}_{\mathrm{c}}=2.04\right)$, a peak associated with broadband shock noise can no longer be identified in the spectrum. A further increase in core pressure $\left(\mathrm{NPR}_{\mathrm{c}}=2.17\right)$ shows a reappearance of the broadband shock noise as well as evidence of a screech tone that is associated with jet oscillation. At the peak jet noise angle given in Fig 16 (b), increasing the core NPR is seen to consistently increase noise levels at most frequencies.

The effect of increasing injection pressure at $\mathrm{NPR}_{\mathrm{c}}=1.82$ and $\mathrm{NPR}_{\mathrm{f}}=2.35$ for the steep fluidic chevron nozzle is shown in Fig. 17. The only effect of fluidic injection at the upstream observation angle appears to be some increase in high frequency noise with increasing IPR. Fig 17 (b) shows only a small decrease in the radiated noise near the peak jet noise angle.

The effect of increasing injection pressure at $\mathrm{NPR}_{\mathrm{c}}=2.04$ and $\mathrm{NPR}_{\mathrm{f}}=2.35$ for the steep fluidic chevron is shown in Fig. 18. Increased injection pressure increases high frequency noise at observation angles upstream of the nozzle exit [see Fig. 18 (a)]. Some decrease in low frequency noise with increasing injection pressure is observed near the peak jet noise angle [see Fig. 18 (b)]. The corresponding sideline directivity in Fig. 19 shows decreases of roughly 2 $\mathrm{dB}$ at the peak jet noise angle as the injection pressure is increased from 1.0 to 5.0.

A comparison of the reductions in overall sound pressure levels between the steep and shallow fluidic chevron nozzles at IPR $=5.0$ is given in Fig. 20. For both nozzles, increased noise levels are observed in the upstream direction due to the increased high frequency injector noise. However, noise reduction is achieved in the downstream direction because of the mixing noise reductions resulting from the air injection. The steep injection yields higher levels of downstream noise reduction that does the shallow injection.

The acoustic spectra acquired at $\mathrm{NPR}_{\mathrm{c}}=2.17$ and $\mathrm{NPR}_{\mathrm{f}}=2.35$ showed that air injection had no effect on the screech or broadband shock noise. Noise reduction in the downstream direction near the peak jet noise angle was achieved with fluidic injection.

The acoustic spectra obtained at the last two operating conditions in Table 2 showed trends similar to those observed in the data acquired at $\mathrm{NPR}_{\mathrm{f}}=2.35$.

\section{Discussion and Conclusions}

Results of the single stream studies indicate that fluidic injection has a large impact on the broadband shock noise radiated from a supersonic jet when a well-defined shock noise peak occurs in the acoustic spectrum. Fluidic injection can alter the stream disturbances produced at the nozzle exit, perturb the shock structure through alteration of the flow conditions at the nozzle exit, and enhance the mixing of the jet. These processes can destroy the correlation between the broadband shock noise sources and hence reduce the shock noise peak. Fluidic injection OASPL reductions of about $2.5 \mathrm{~dB}$ were obtained at upstream observation angles for a cold jet operating at NPR = 2.17. In contrast, a hot jet, which lacks such a well-defined shock noise peak, resulted in a corresponding reduction of only about $1 \mathrm{~dB}$ when operated at the higher NPR of 2.30. On the other hand, in the downstream jet mixing noise dominated direction, OASPL reductions of about $3 \mathrm{~dB}$ were obtained for both the hot and cold jets.

In the dual stream jet experiments, well-defined shock noise peaks occur when the fan stream is at supersonic speeds and the core is subsonic. When the core NPR is increased to values slightly higher than the critical value for supersonic flow, the broadband shock noise is greatly reduced. A further increase in the core NPR results in broadband shock noise again increasing.

Core air injection was effective at reducing broadband shock noise with the fan stream at NPR $=2.23$ and the core stream subsonic, probably due to perturbations of the fan-stream shock-cell structure caused by enhanced mixing between the two streams. Reductions in OASPL of $2 \mathrm{~dB}$ were obtained. However, at the higher fan pressure of $\mathrm{NPR}_{\mathrm{f}}=2.35$, core air injection has little effect on broadband shock noise. The higher pressure in the fan stream 
may limit mixing by air injected into the core stream and hence limit the impact on the shock cell structure. For higher fan pressures, injection into the fan stream may be required for broadband shock noise reduction, since the injection would then directly impact both the shock cells and the disturbances in the outer shear layer.

As with the single nozzle, fluidic injection results in increased reductions in mixing noise near the peak jet noise angle with increasing core NPR. Reductions greater than $2 \mathrm{~dB}$ in OASPL were obtained.

\section{Acknowledgments}

The air injection nozzles used in these experiments were jointly designed by NASA Langley Research Center and Goodrich Aerostructures under SAA1-561.

\section{References}

${ }^{1}$ Janardan, B., Yamamoto, K., Majjigi, R., and Brausch, J., "Experimental Investigation of shock-cell noise reduction for dual-stream nozzles in simulated flight,” NASA CP 3846, 1984.

${ }^{2}$ Harper-Bourne, M., and Fisher, M., “The noise from shock waves in supersonic jets,” Proceedings of AGARD Conference on Noise Mechanisms, AGARD CP-131, 1973.

${ }^{3}$ Tam, C., "Stochastic model theory of broadband shock associated noise from supersonic jets," J. Sound and Vib., Vol 116, pt. 2, pp. 265 - 302, 1987.

${ }^{4}$ Tam, C., "Broadband shock-associated noise from supersonic jets in flight,” J. Sound and Vib., Vol. 151, pt. 1, pp. 131 147, 1991.

${ }^{5}$ Bhat, T., Ganz, U., and Guthrie, A., “Acoustic \& flow-field characteristics of shock-cell noise from dual flow nozzles,” AIAA-2005-2929, 2005.

${ }^{6}$ Pack, D. C., “A note on Prandtl's formula for the wave-length of a supersonic gas jet," Quart. Journal of Mechanics and Applied Math., Vol. III, pt. 2, pp. 173 - 181, 1950.

${ }^{7}$ Greska, B., and Krothapalli, A., “Jet noise reduction using aqueous microjet injection,” AIAA-2004-2971, 2004.

${ }^{8}$ Norum, T., "Reductions in multi-component jet noise by water injection,” AIAA-2004-2976, 2004.

${ }^{9}$ Janardan, B., Hoff, G., Barter, J., Martens, S., and Gliebe, P., "AST critical propulsion and noise reduction technologies for future commercial subsonic engines,” NASA/CR - 2000-210039, 2000.

${ }^{10}$ Kinzie, K., Henderson, B., Whitmire, J., and Abeysinghe, A., "Fluidic chevrons for jet noise reduction,” Proceedings of The 2004 International Symposium on Active Control of Sound and Vibration (ACTIVE 04), INCE/USA, Williamsburg, VA, 2004.

${ }^{11}$ Henderson, B., Kinzie, K., Whitmire, J., and Abeysinghe, A., “Impact of fluidic chevrons on jet noise,” AIAA-2005-2888, 2005.

${ }^{12}$ Shields, F. D. and Bass, H. E., “A study of atmospheric absorption of high frequency noise and application to fractional octave bands of noise,” NASA Contractor Report 2760, 1976. 

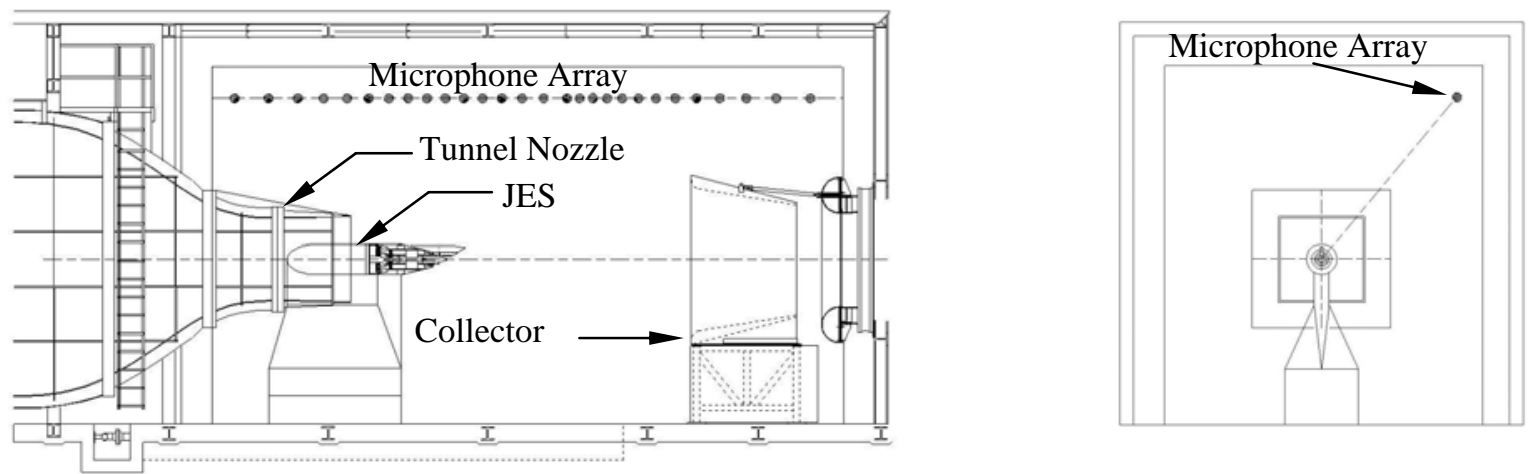

Figure 1. A schematic of the Low Speed Aeroacoustics Wind Tunnel (LSAWT) and the Jet Engine Simulator (JES).

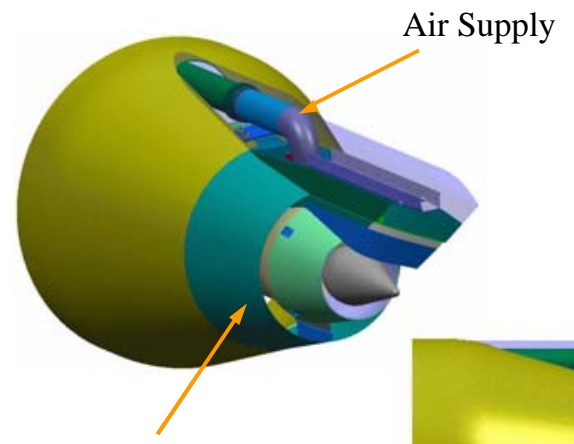

Fan Nozzle

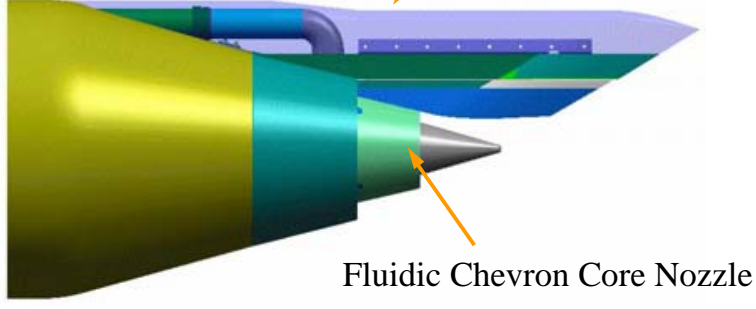

Figure 2. A schematic of the bypass ratio 5 model system used in the experiments.

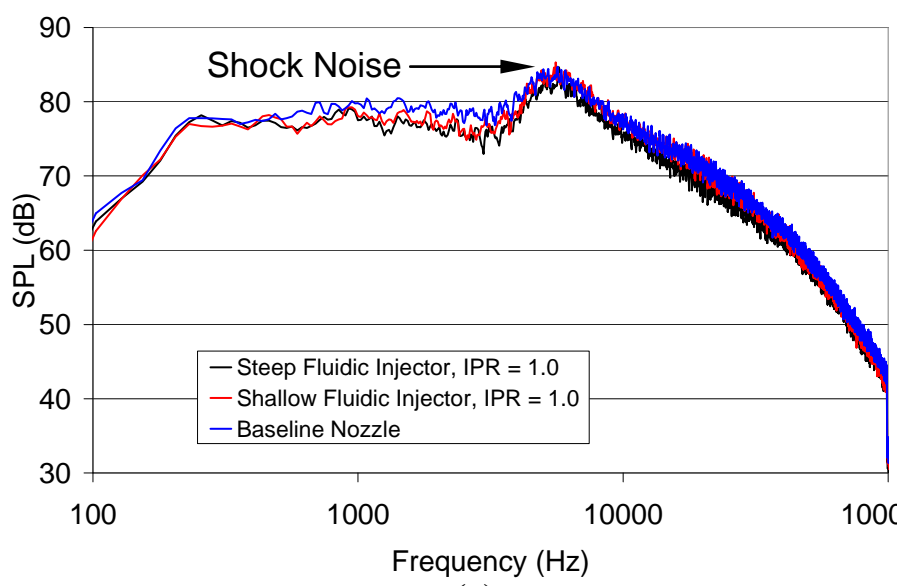

(a)

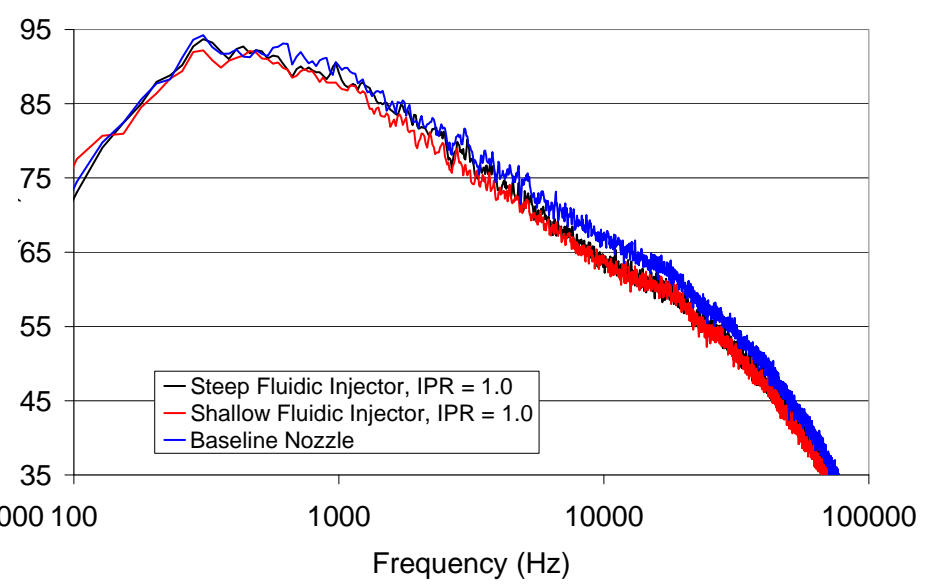

(b)

Figure 3. Plots of the narrowband power spectra for the steep fluidic injector (with no air injection), the shallow fluidic injector (with no air injection), and the baseline nozzle at a core NPR of 2.17. The observation angles are (a) $61^{\circ}$ and (b) $148^{\circ}$. 


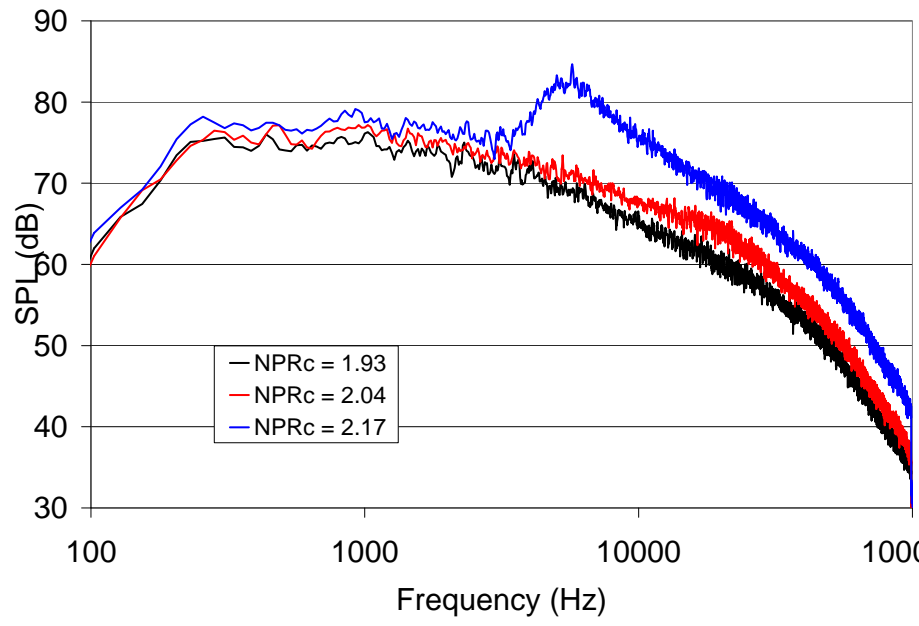

(a)

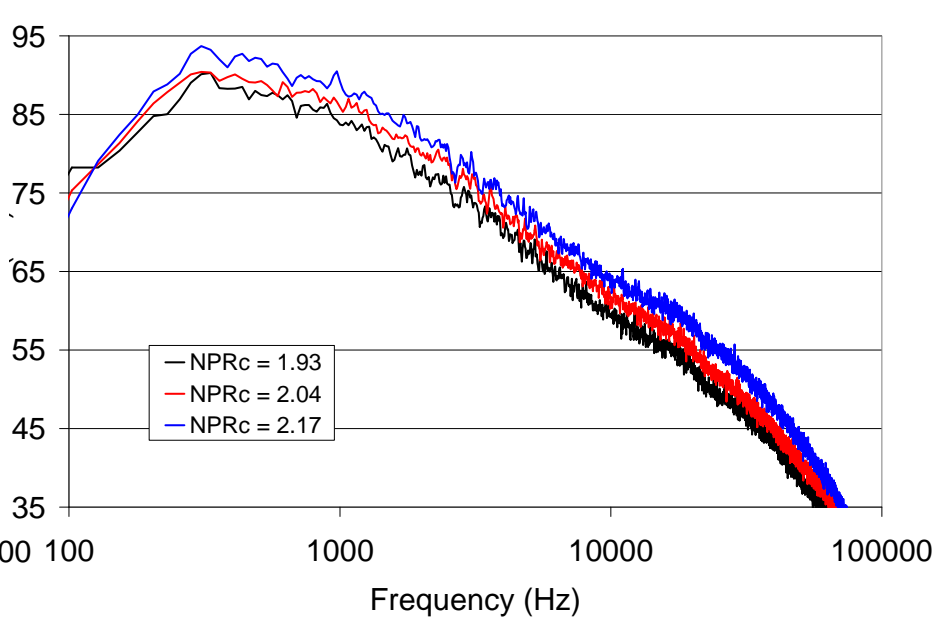

(b)

Figure 4. Plots of the narrowband power spectra for the steep fluidic injector (with no air injection) at $N_{P R}$ between 1.93 and 2.30. The observation angles are (a) $61^{\circ}$ and (b) $148^{\circ}$.



(a)

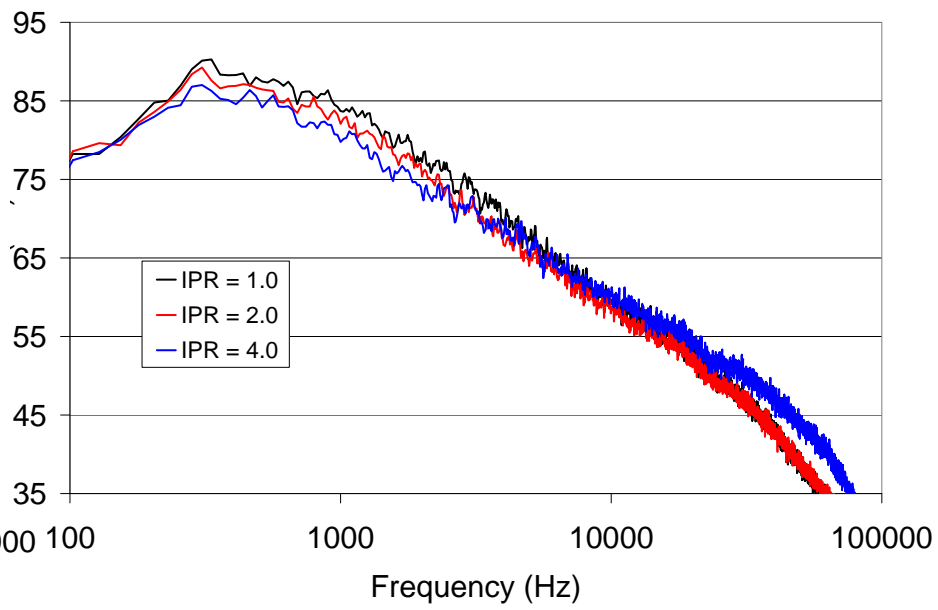

(b)

Figure 5. Plots of the narrowband power spectra for the steep fluidic chevron operated at different injection pressure ratios (IPR) and a core NPR of 1.93 . The observations angles are (a) $61^{\circ}$ and (b) $148^{\circ}$.

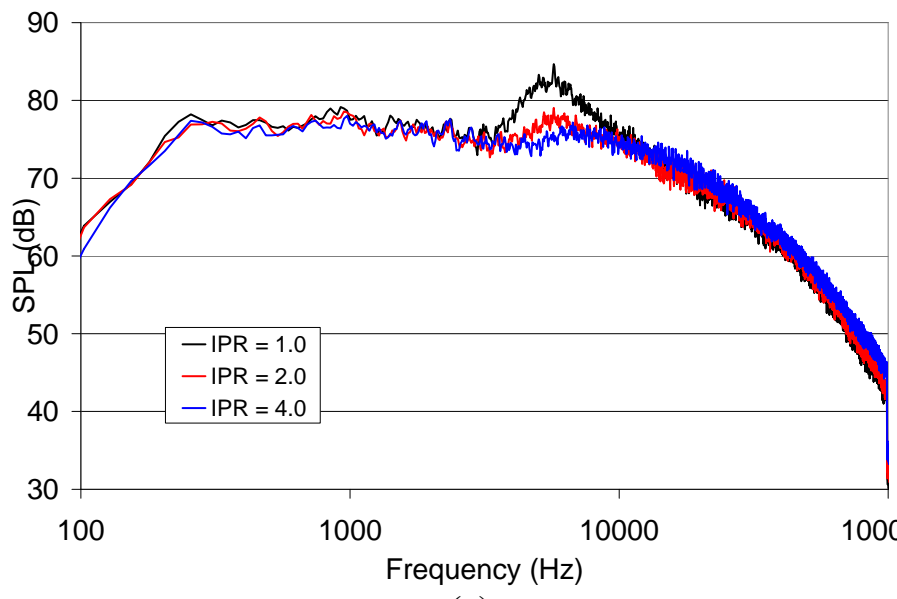

(a)

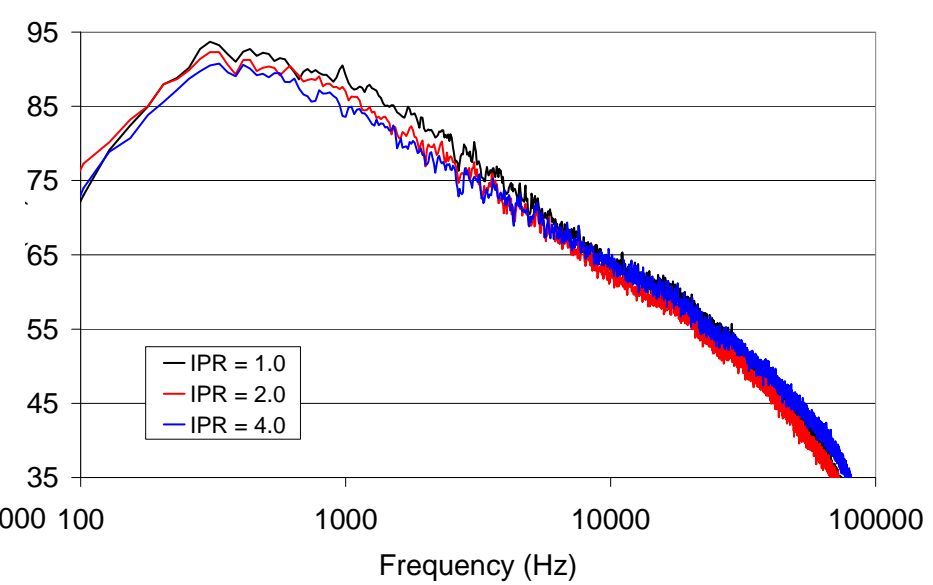

(b)

Figure 6. Plots of the narrowband power spectra for the steep fluidic inject operated at different injection pressure ratios (IPR) and a core NPR of 2.17. The observations angles are (a) $61^{\circ}$ and (b) $148^{\circ}$. 


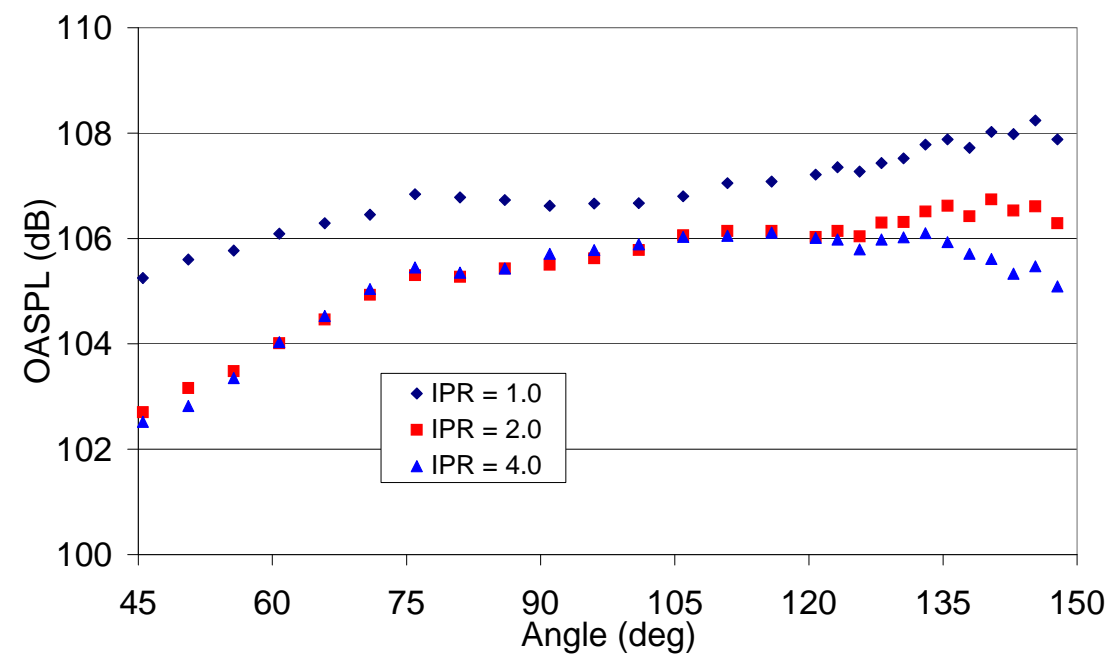

Figure 7. The sideline directivity for the steep fluidic chevron at $\mathrm{NPR}_{\mathrm{c}}=\mathbf{2 . 1 7}$.

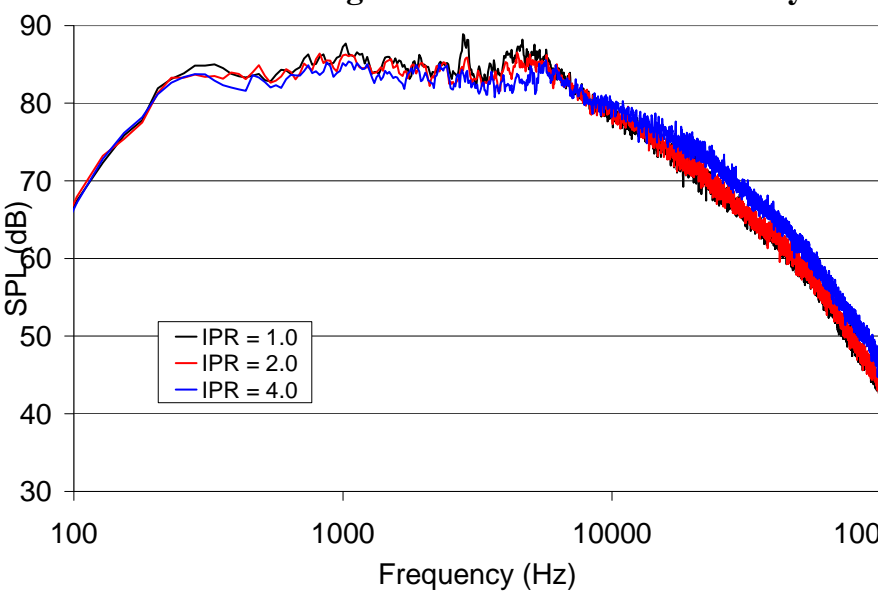

(a)

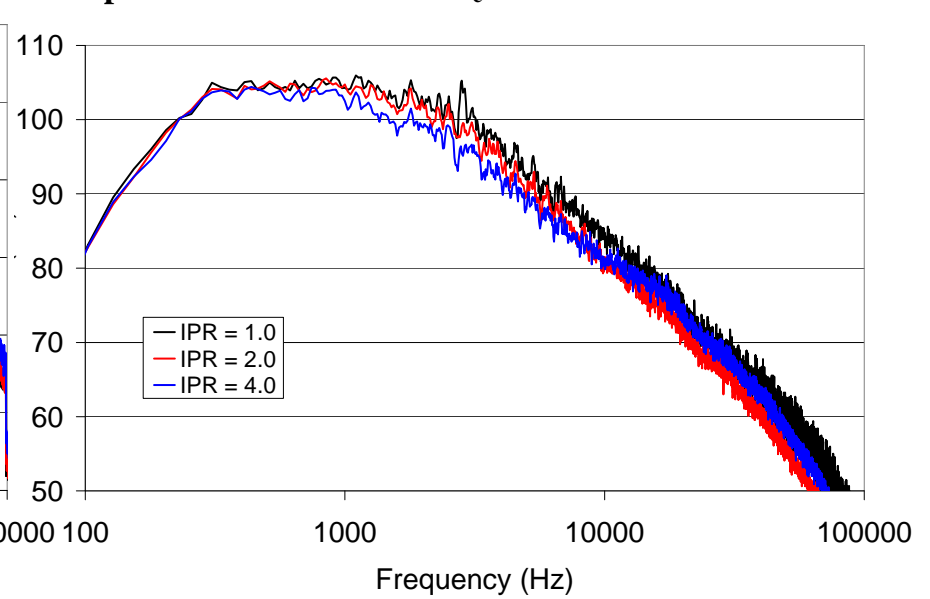

(b)

Figure 8. Plots of the narrowband power spectra for the steep fluidic chevron at $\mathbf{N P R}_{\mathrm{c}}=2.3$ and $\mathrm{TTR}_{\mathrm{c}}=2.5$. The observations angles are (a) $61^{\circ}$ and (b) $148^{\circ}$.

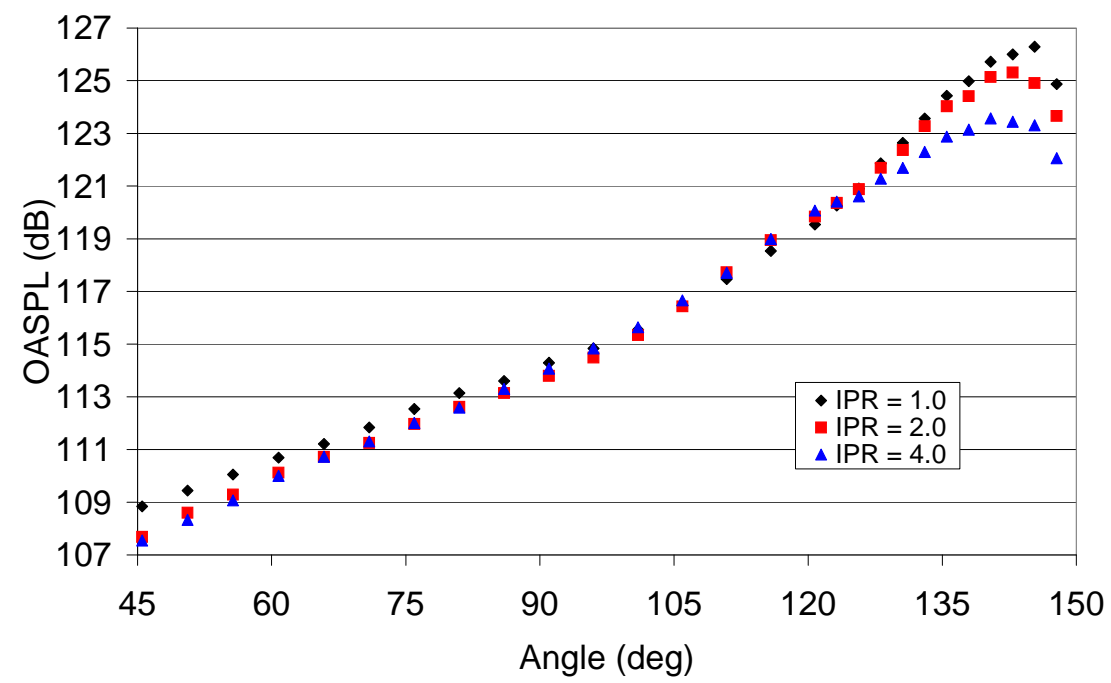

Figure 9. The sideline directivity for the steep fluidic chevron at $\mathrm{NPR}_{\mathrm{c}}=2.3$ and $\operatorname{TTR}_{\mathrm{c}}=\mathbf{2 . 5}$. 


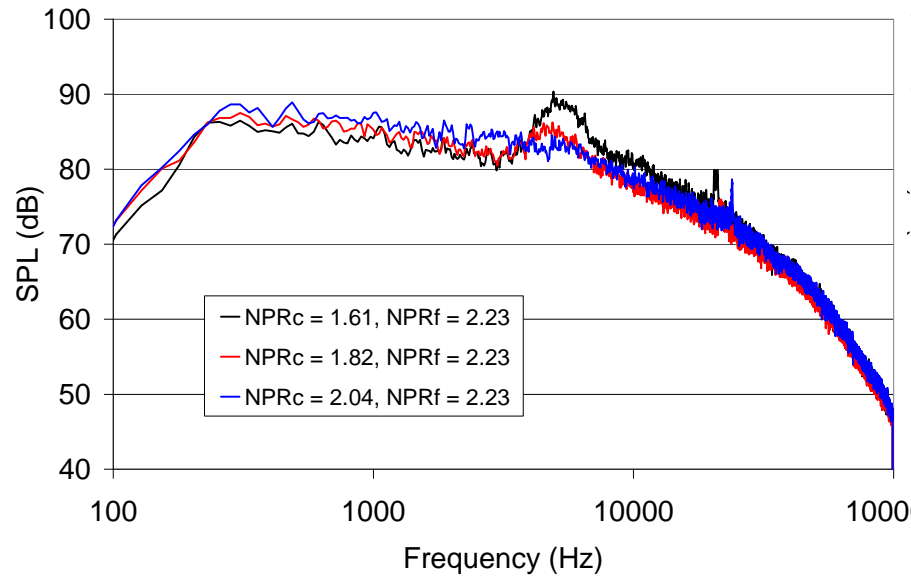

(a)

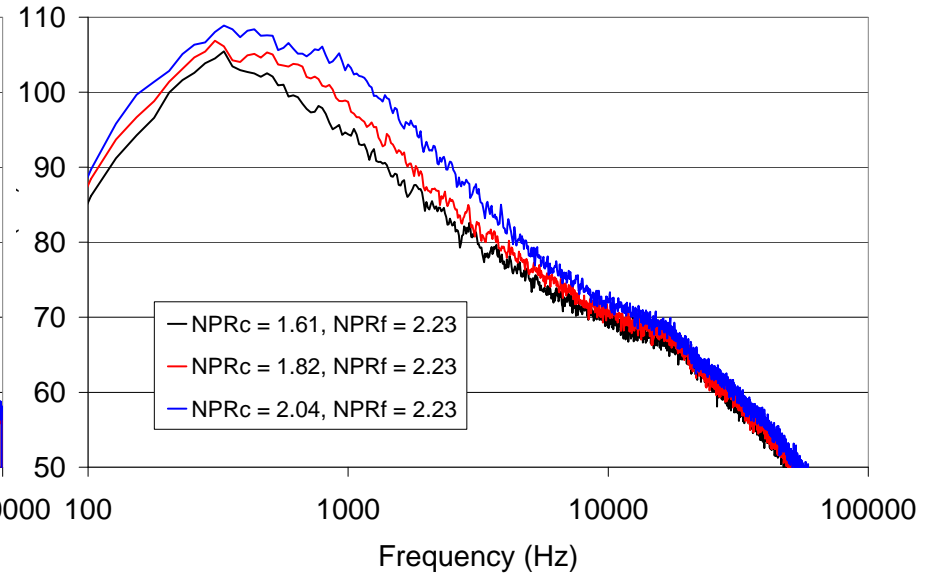

(b)

Figure 10. The narrowband power spectra for the steep fluidic chevron nozzle $(I P R=1.0)$ at $N P R_{f}=2.23$ and $\mathrm{NPR}_{r}=1.61,1.82$, and 2.04. The observation angles are (a) $61^{\circ}$ and (b) $148^{\circ}$.

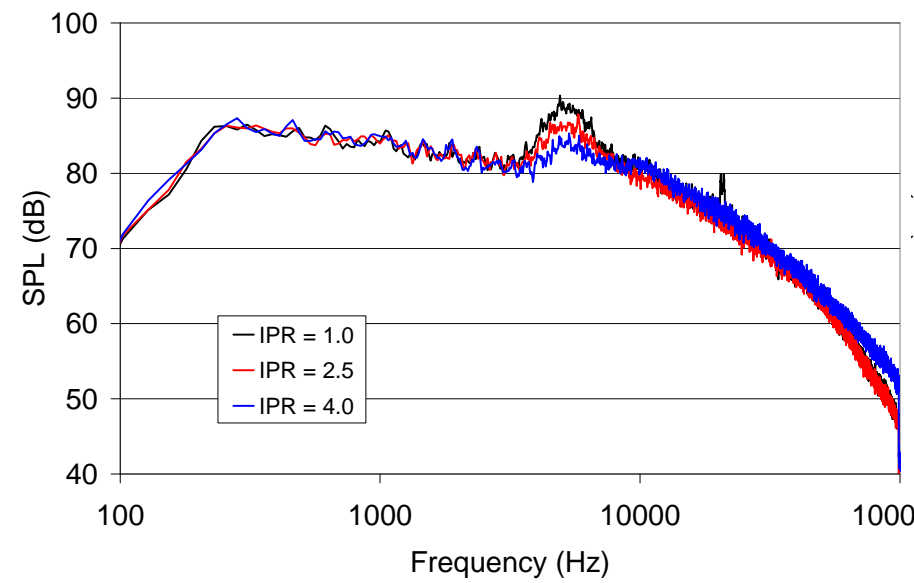

(a)

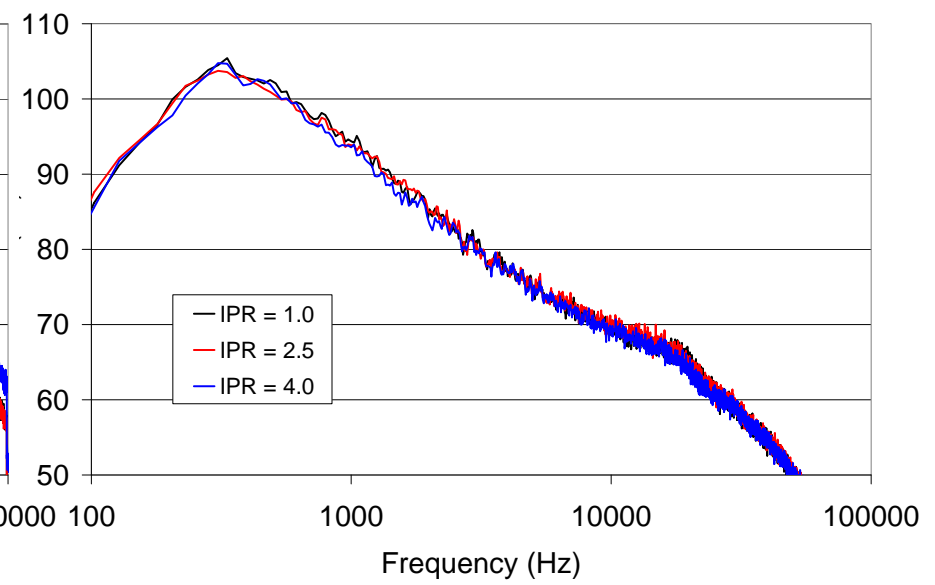

(b)

Figure 11. The narrowband power spectra for the steep fluidic chevron at $\mathrm{NPR}_{\mathrm{f}}=2.23$ and $\mathrm{NPR}_{\mathrm{c}}=\mathbf{1 . 6 1}$. The observation angles are (a) $61^{\circ}$ and (b) $148^{\circ}$.

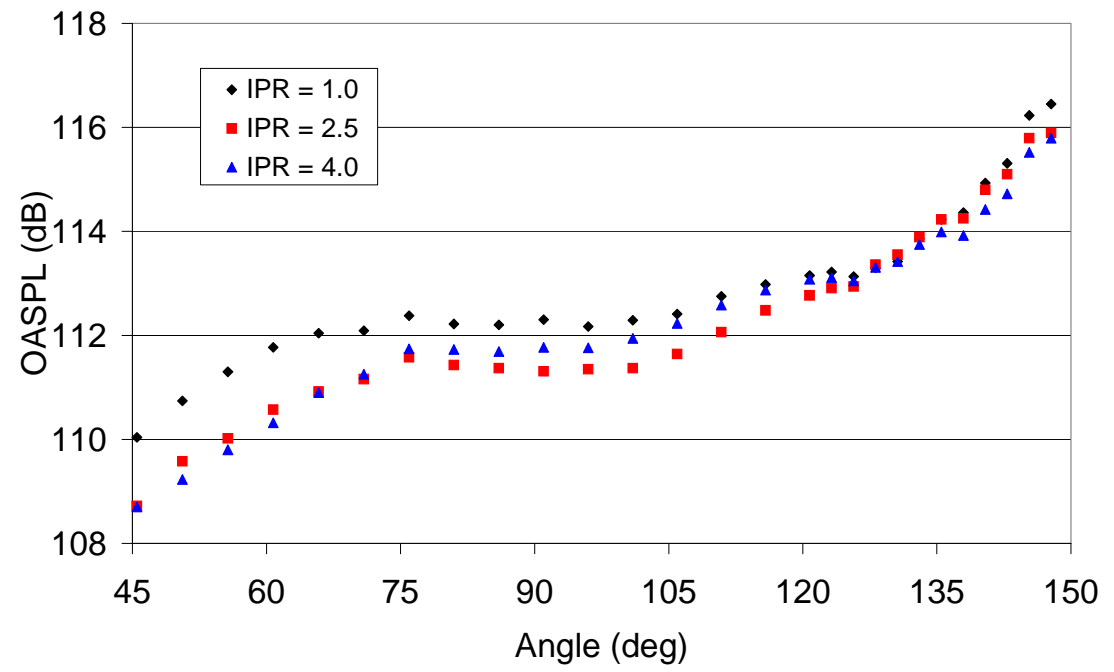

Figure 12. The sideline directivity for the steep fluidic chevron at $\mathrm{NPR}_{\mathrm{f}}=2.23$ and $\mathrm{NPR}_{\mathrm{c}}=\mathbf{1 . 6 1}$. 


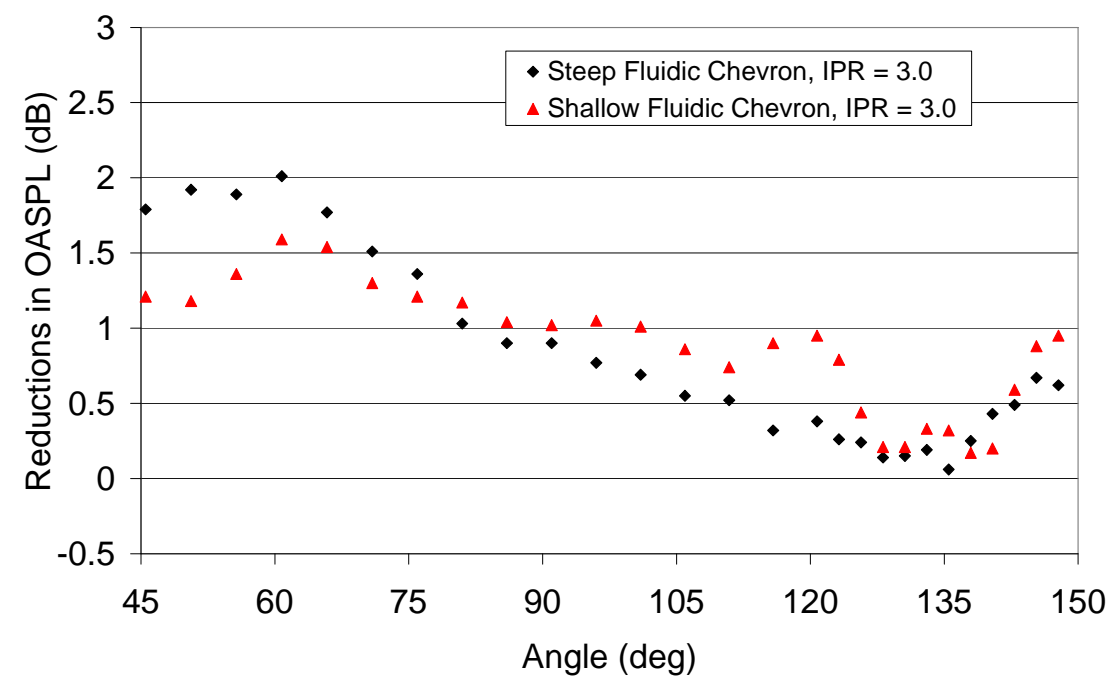

Figure 13. Overall sound pressure level reductions for the steep and shallow fluidic chevron nozzles at $\mathrm{NPR}_{\mathrm{f}}=\mathbf{2 . 2 3}$ and $\mathrm{NPR}_{\mathrm{c}}=\mathbf{1 . 6 1}$.

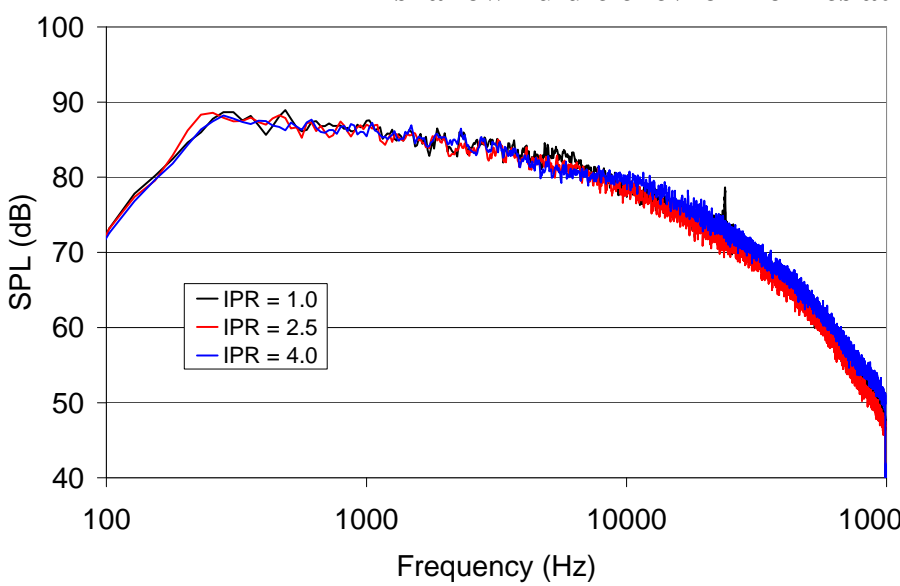

(a)

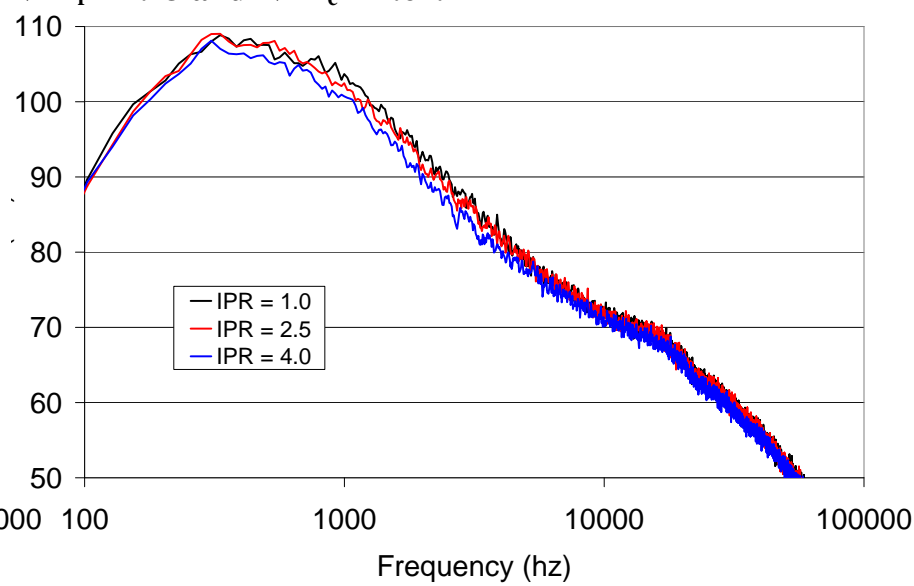

(b)

Figure 14. The narrowband power spectra for the steep fluidic chevron at $\mathrm{NPR}_{\mathrm{f}}=2.23$ and $\mathrm{NPR}_{\mathrm{c}}=2.04$. The observation angles are (a) $61^{\circ}$ and (b) $148^{\circ}$.

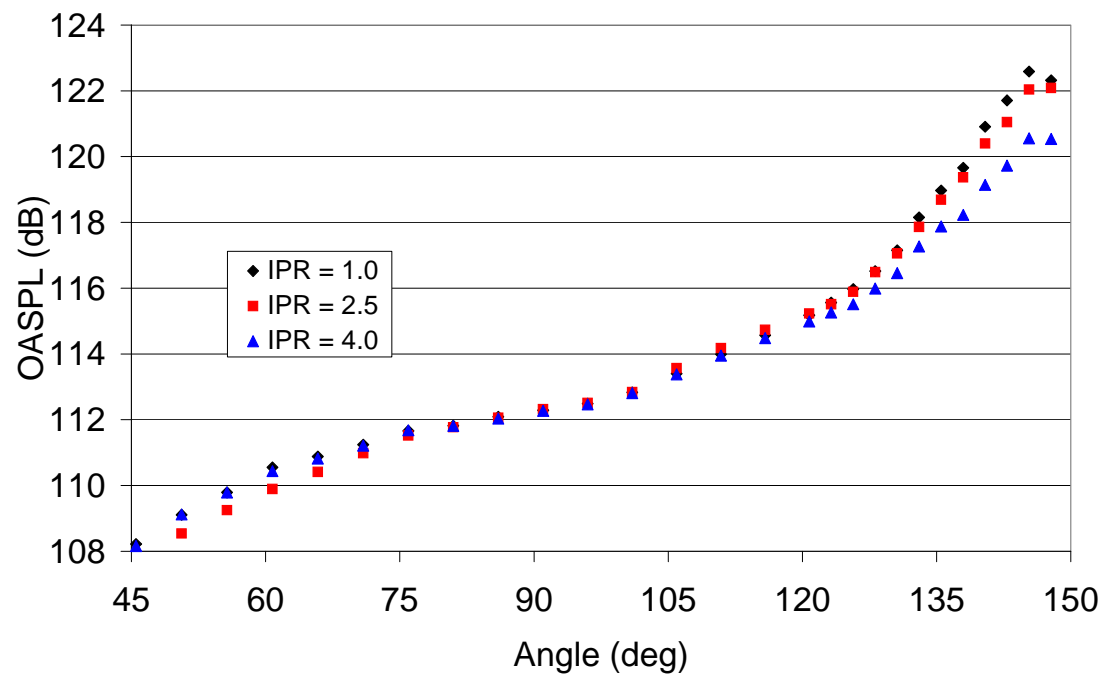

Figure 15. The sideline directivity for the steep fluidic chevron at $\mathrm{NPR}_{\mathrm{f}}=2.23$ and $\mathrm{NPR}_{\mathrm{c}}=2.04$. 


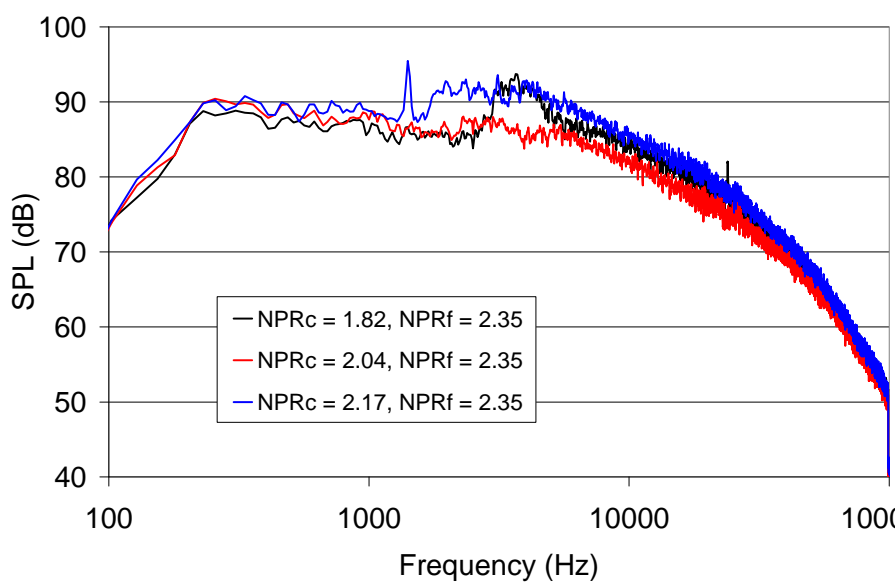

(a)

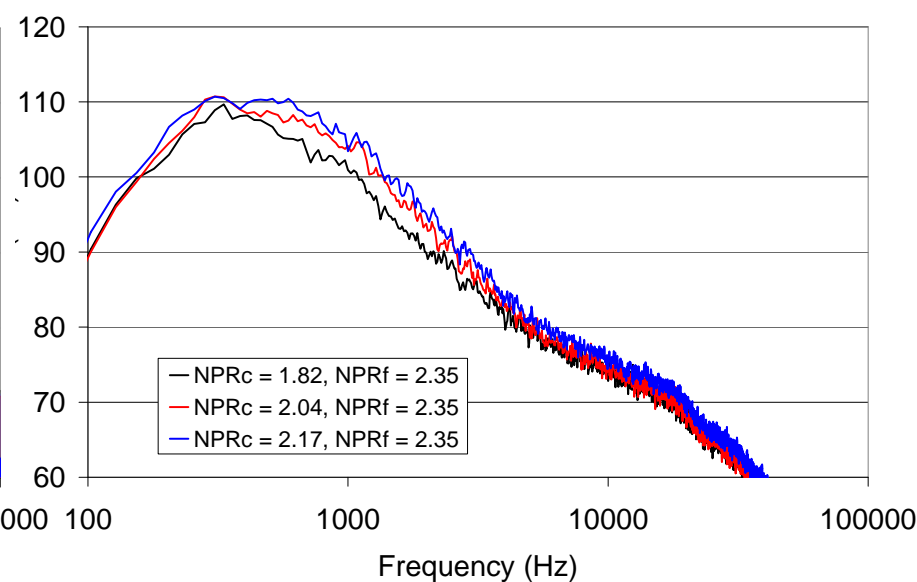

(b)

Figure 16. The narrowband power spectra for the steep fluidic chevron nozzle at $\mathbf{N P R}_{\mathrm{f}}=\mathbf{2 . 3 5}$ and $\mathbf{N P R} \mathrm{c}=\mathbf{1 . 8 2}$, 2.04, and 2.17. The observation angles are (a) $61^{\circ}$ and (b) $148^{\circ}$.

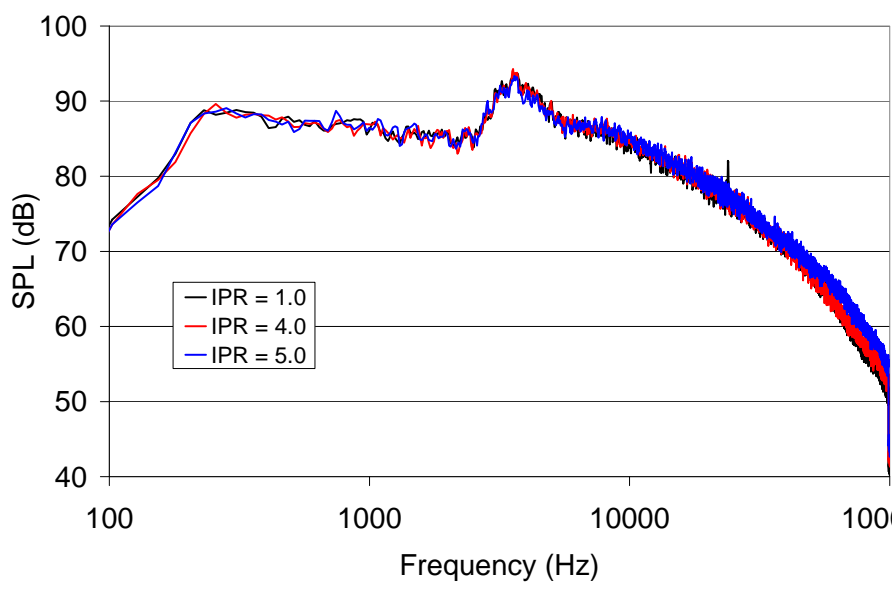

(a)

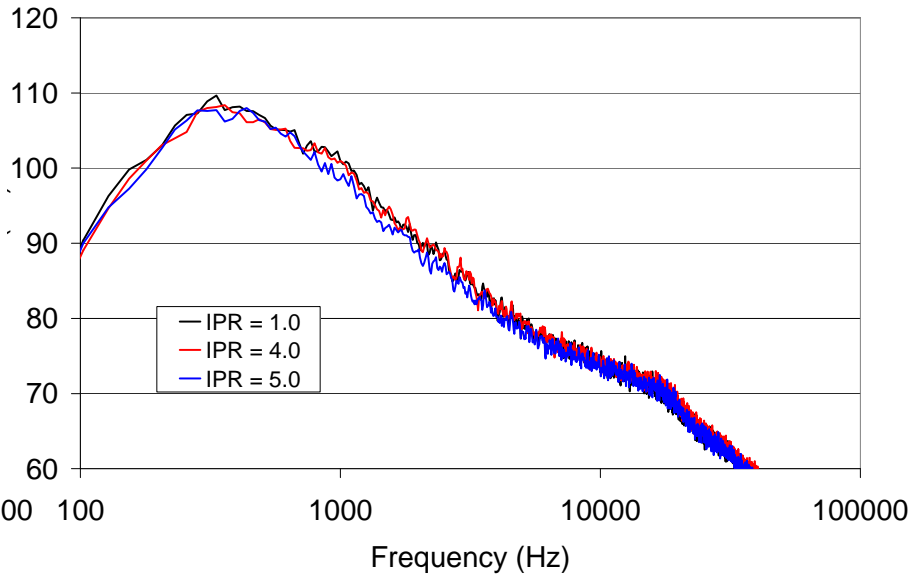

(b)

Figure 17. The narrowband power spectra for the steep fluidic chevron at $\mathrm{NPR}_{\mathrm{f}}=\mathbf{2 . 3 5}$ and $\mathbf{N P R _ { \mathrm { c } }}=\mathbf{1 . 8 2}$. The observation angles are (a) $61^{\circ}$ and (b) $148^{\circ}$.

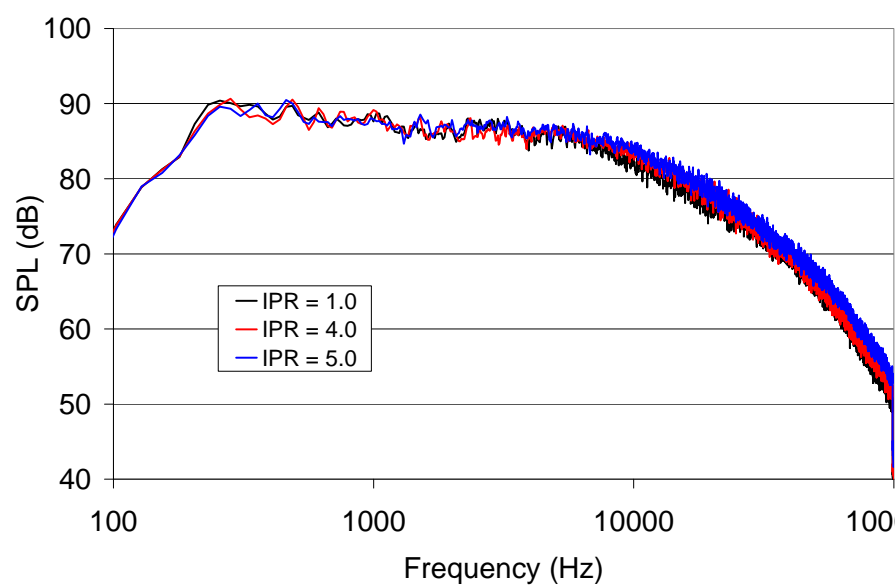

(a)

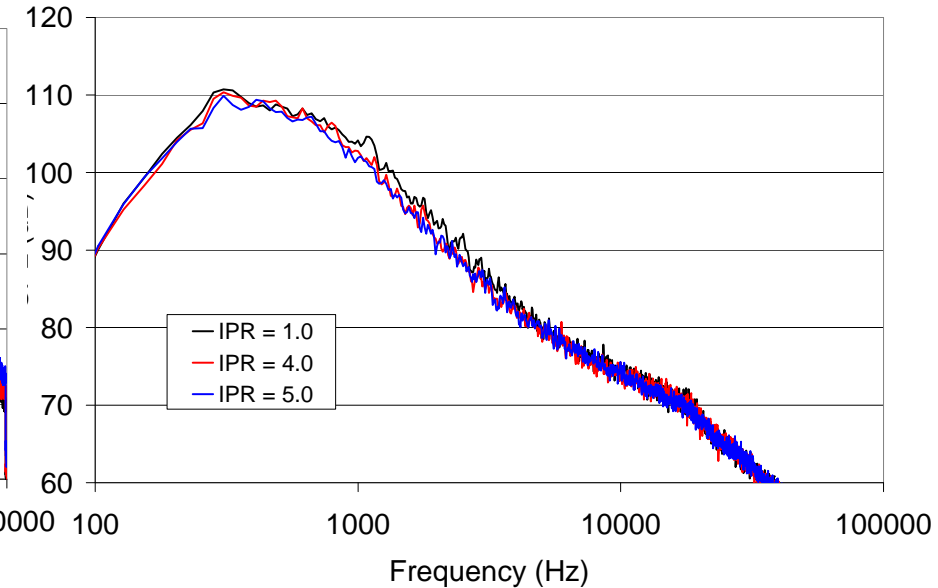

(b)

Figure 18. The narrowband power spectra for the steep fluidic chevron at $\mathrm{NPR}_{\mathrm{f}}=2.35$ and $\mathrm{NPR}_{\mathrm{c}}=\mathbf{2 . 0 4}$. The observation angles are (a) $61^{\circ}$ and (b) $148^{\circ}$. 


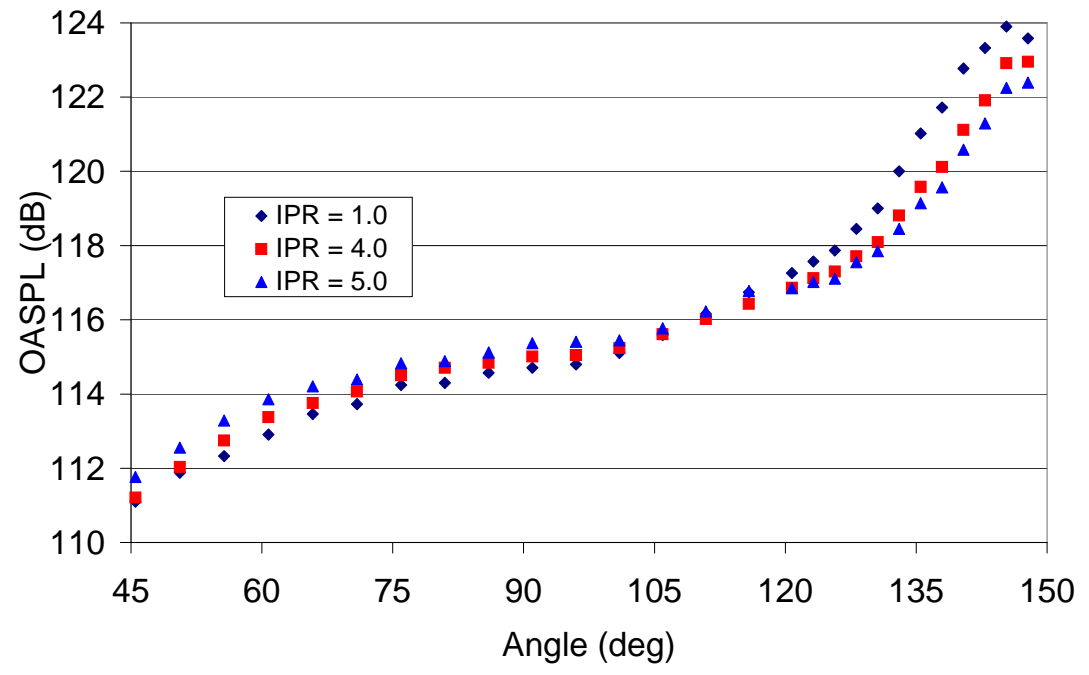

Figure 19. The sideline directivity for the steep fluidic chevron at $\mathbf{N P R}_{\mathrm{f}}=\mathbf{2 . 3 5}$ and $\mathrm{NPR}_{\mathrm{c}}=\mathbf{2 . 0 4}$

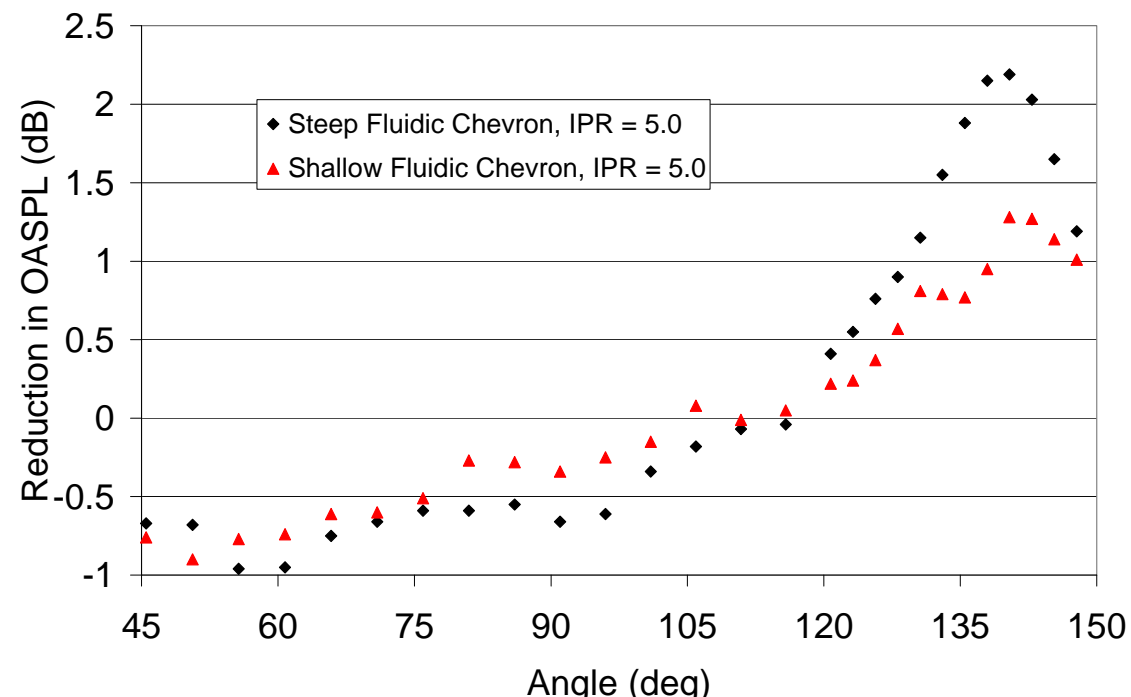

Figure 20. Overall sound pressure level reductions for the steep and shallow fluidic chevron nozzles at $\mathrm{NPR}_{\mathrm{f}}=2.35$ and $\mathrm{NPR}_{\mathrm{c}}=2.04$. 